\title{
KARAKTERISTIK PASIEN SKIZOFRENIA RAWAT JALAN DI POLI JIWA RSUD. DR. H. MOCH. ANSARI SALEH BANJARMASIN
}

\section{Characteristics Of Patients Schizophrenia Outpatient In Poly Of Soul Rsud. Dr. H. Moch. Ansari Saleh Banjarmasin}

\author{
Muliyani ${ }^{1}$, Nazhipah Isnani ${ }^{2}$ \\ ${ }^{1}$ Program Studi D-III Farmasi. Politeknik Unggulan Kalimantan \\ Email: muliyani@polanka.ac.id
}

\begin{abstract}
ABSTRACK
Shizophrenia is a mental disorder that affects brain fuction and causes disturbances in thoughts, perception, emotions, movement, and behavior. The incidence of schizophrenia in the community is very high (Videbeck, 2008). Based on data from the World Health Organization (WHO) in 2013 stated that chiziphrenia is a mental illness that attacks nearly 24 million people worldwide, more than $50 \%$ of schizophrenia do not get the right service and $90 \%$ of untreated schizophrenia patients are in developing countries.

This study aims to determine the characteristics of schizophrenia patients. The research method is a cross-sectional observational study taking patient data prospectively. The sample population was all schizophrenia patient who underwent outpatient treatment for 12 month at the outpatient psychiatric hospital of Dr. H. Moch. Ansari Saleh Banjarmasin who met the inclusion criteria. The results showed male sex characteristics by $56 \%$ and women by $44 \%$, the highest incidence in the age range of $22-45$ years by $52 \%$ with paranoid schizophrenia by $44 \%$ and unspecified by $45 \%$.
\end{abstract}

Keywords: Schizophrenia, patient criteria, outpatient

\begin{abstract}
ABSTRAK
Skizofrenia adalah suatu gangguan kejiwaan yang mampu mempengaruhi fungsi otak seseorang serta menyebabkan munculnya perubahan pikiran, persepsi, perubahan gerakan dan perilaku. Kejadian skizofrenia di masyarakat sangat tinggi (Videbeck, 2008). Berdasarkan data World Health Organization (WHO) tahun 2013 disebutkan bahwa skizofrenia merupakan penyakit gangguan kejiwaan yang menyerang hampir 24 juta masyarakat di seluruh dunia, $50 \%$ bahkan lebih penderita skizofrenia tidak mendapatkan pelayanan yang tepat dan penderita skizofrenia yang tidak dilakukan perawatan berada di negara berkembang sebesar $90 \%$. Tujuan dari penelitian ini adalah untuk mengetahui karakteristik pasien skizoprenia. Metode penelitian merupakan penelitian Observasional Crossectional dengan pengambilan secara prosfektif pada data pasien. Populasi sampel adalah semua pasien skizofrenia yang menjalani pengobatan rawat jalan selama 12 bulan di Poli Jiwa Rawat Jalan RSUD dr. H. Moch. Ansari Saleh Banjarmasin yang termasuk kriteria inklusi. Hasil Penelitian menunjukkan karakteristik jenis kelamin laki-laki sebesar $56 \%$ dan perempuan sebesar $44 \%$, kejadian tertinggi pada rentang usia $22-45$ tahun sebesar $52 \%$ dengan jenis skizofrenia paranoid sebesar $44 \%$ dan tak terinci sebesar $45 \%$.
\end{abstract}

Kata kunci : Skizofrenia, kriteria pasien, rawat jalan 


\section{PENDAHULUAN}

Skizofrenia adalah suatu gangguan kejiwaan yang mampu mempengaruhi fungsi otak seseorang serta menyebabkan munculnya perubahan pikiran, persepsi, perubahan gerakan dan perilaku. Kejadian skizofrenia di masyarakat sangat tinggi (Videbeck, 2008). Berdasarkan data World Health Organization (WHO) tahun 2013 disebutkan bahwa skizofrenia merupakan penyakit gangguan kejiwaan yang menyerang hampir 24 juta masyarakat di seluruh dunia, $50 \%$ bahkan lebih penderita skizofrenia tidak mendapatkan pelayanan yang tepat dan penderita skizofrenia yang tidak dilakukan perawatan berada di negara berkembang sebesar $90 \%$.

Skizoprenia adalah suatu gangguan kejiwaan yang mampu mempengaruhi fungsi otak seseorang serta menyebabkan munculnya perubahan pikiran, persepsi, perubahan gerakan dan perilaku aneh (Videbeck, 2008). Menurut DSM-IV-TR (Diagnostik and Statistical Manual of Mental Disorders), 2000 (dalam Videback, 2008). Skizofrenia terdiagnosis pada usia remaja akhir dan usia dewasa awal. Awal terjadinya skizofrenia pada usia 25-35 tahun untuk perempuan dan 15-25 tahun untuk laki-laki. Skizofrenia merupakan salah satu masalah kesehatan yang cukup banyak di Indonesia. Penderita skizoprenia masih pada angka yang tinggi yaitu, $80 \%$ tidak ditangani dengan pengobatan oleh keluarga dan tim medis. Peningkatan pasien skizoprenia terjadi seiring dengan banyaknya pasien yang dipasung oleh keluarga serta dibiarkan berada di jalanan (Susanto, 2009).

Salah satu negara yang memiliki angka kejadian penyakit skizofrenia yang relatif cukup tinggi adalah Indonesia. Di Indonesia angka Prevalensi skizofrenia pada tahun 2013 yakni sebesar 1,7 per seribu penduduk dan diperkirakan sekitar 1 juta penduduk Indonesia mengalami skizofrenia. Prevalensi skizofrenia di Provinsi Kalimantan Selatan sebesar 1,4 per seribu penduduk (Riskesdas, 2013). Berdasarkan latar belakang tersebut, maka perlu dilakukan penelitian untuk menegtahui karakyteristik dan angka kejadian pada pasien skizofrenia di rawat jalan di Rumah Sakit Umum Daerah DR. H.Moch. Ansari Saleh.

\section{METODE PENELITIAN}

Metode penelitian merupakan penelitian Observasional Crossectional dengan pengambilan prosfektid data pasien. Penelitian dilakukan di Poli Jiwa RSUD dr. H. Moch. Ansari Saleh Banjarmasin. Penelitian ini dilakukan pada periode bulan Mei- Juni 2018. Jenis data yang digunakan adalah data primer dan sekunder. Data primer diperoleh dengan cara wawancara dan pengisian kuisioner terstuktur oleh pasien, sedangkan data sekunder diambil dari catatan medis pasien.

\section{HASIL DAN PEMBAHASAN}

Pengambilan sampel pada penelitian ini sebanyak 50 pasien skizofrenia yang telah memenuhi kriteria inklusi penelitian yang diambil dari Poli Jiwa Rawat Jalan dan ruangan Rekam Medis RSUD dr. H. Moch. Ansari Saleh Banjarmasin.

\section{Gambaran Umum Karakteristik Subyek Penelitian}

Gambaran umum karakteristik pasien skizofrenia dapat dilihat berdasarkan jenis kelamin, umur dan jenis skizofrenia.Gambaran umum karakteristik pasien skizofrenia lebih jelasnya dapat dilihat pada tabel 1. 


\begin{tabular}{lcc}
\multicolumn{3}{l}{ Tabel 1. Gambaran umum karakteristik pasien skizofrenia } \\
\hline Karakteristik Berdasarkan & N=50 & Persentase (\%) \\
\hline Jenis Kelamin & 28 & $56 \%$ \\
Laki-laki & 22 & $44 \%$ \\
Perempuan & 1 & $2 \%$ \\
Umur & 26 & $52 \%$ \\
18-21 tahun & 21 & $42 \%$ \\
$22-45$ tahun & 2 & $4 \%$ \\
46-55 tahun & & \\
$>56$ tahun & & \\
Jenis Skizofrenia & 22 & $44 \%$ \\
Skizofrenia Paranoid (F20.0) & 28 & $56 \%$ \\
Skizofrenia Tak Terinci (F20.3) & 0 & $0 \%$ \\
Skizofrenia Hebefrenik (F20.1) & 0 & $0 \%$ \\
Skizofrenia Katatonia (F20.2) & 0 & $0 \%$ \\
Skizofrenia Simplek (F20.6) & & \\
\end{tabular}

Berdasarkan tabel 1, hasil gambaran umum karakteristik penelitian berdasarkan, jenis kelamin, umur dan jenis skizofrenia dapat diuraikan sebagai berikut :

1) Berdasarkan Jenis Kelamin

Hasil penelitian berdasarkan karakteristik jenis kelamin di Poli Jiwa Rawat Jalan RSUD dr. H. Moch. Ansari Saleh Banjarmasin yang diperoleh berdasarkan data pada tabel 1. karakteristik jenis kelamin laki-laki berjumlah 28 orang (56\%) dan karakteristik berjenis kelamin perempuan berjumlah 22 orang (44\%). Dari data yang diperoleh menunjukkan bahwa pasien skizofrenia dengan jenis kelamin laki-laki lebih dominan dibandingkan pasien skizofrenia jenis kelamin perempuan sesuai dengan hasil penelitian Kaunang (2015) dimana karakteristik berdasarkan jenis kelamin pada pasien skizofrrenia menunjukkan persentase jenis kelamin laki-laki sebanyak $56 \%$ lebih tinggi dibandingkan jenis kelamin perempuan dengan persentase sebanyak $44 \%$.

Penelitian yang dilakukan oleh Naafi (2016) juga menunjukkan bahwa persentase yang mengalami skizofrenia lebih tinggi yaitu pada kelompok laki-laki sebesar $(60 \%)$ dan kelompok perempuan sebesar (40\%). Penelitian yang dilakukan oleh Agung (2016) juga menunjukkan bahwa ada hubungan antara jenis kelamin dengan kejadian skizofrenia. Dimana jenis kelamin laki-laki faktor resiko lebih besar yaitu, 6,038 kali untuk bisa terkena skizofrenia dibandingkan perempuan. Sesuai dengan teori Adamo (2007) yang menyebutan bahwa laki-laki memiliki kecenderungan menunjukkan resiko tinggi mengalami skizofrenia dikarenakan laki-laki cenderung memiliki produksi hormon stress yang berlebihan. Dapat dilihat pada gambar 1. Berikut:

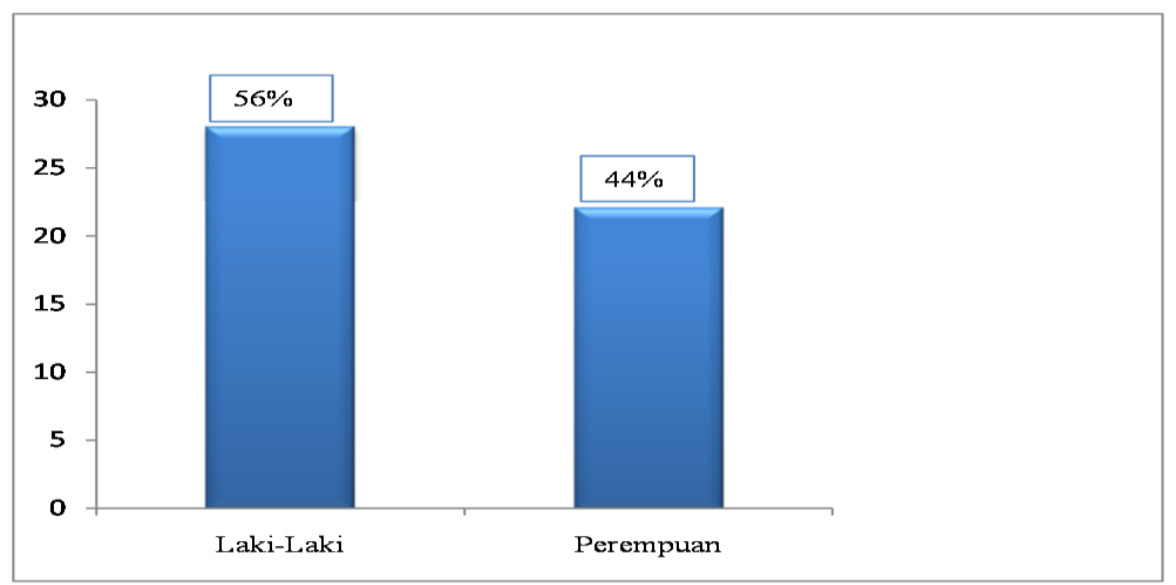

Gambar 1. Karakteristik pasien skizofrenia berdasarkan umur

2) Berdasarkan Umur

Distribusi umur pasien skizofrenia di Poli Jiwa Rawat Jalan RSUD dr. H. Moch. Ansari Saleh Banjarmasin berdasarkan tabel 1. menunjukkan prevalensi terbanyak adalah yang 
berumur pada rentang 22-45 tahun berjumlah 26 orang (52\%). Penelitian yang dilakukan oleh Lina Handayani (2015) juga menunjukkan bahwa pasien skizofrenia terjadi pada rentang umur 25-44 tahun dengan persentase sebesar (55,7\%). Pendapat ini juga dikuatkan oleh penelitian Fahrul (2014) yang menyatakan bahwa umur yang terbanyak pada pasien berjenis kelamin laki-laki maupun perempuan adalah yang berumur antara 26-45 tahun yaitu $66,1 \%$ dan 73,3\%. Digambarkan dalam grafik gambar 2 .

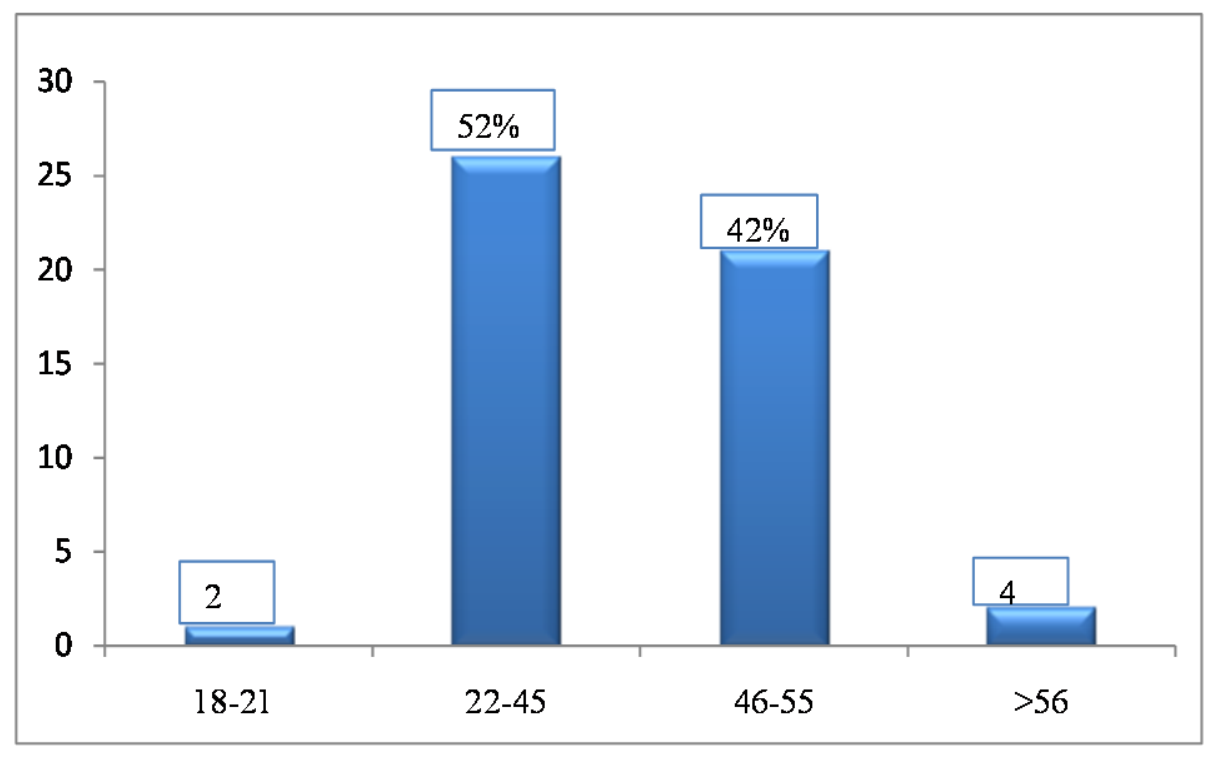

Gambar 2. Karakteristik pasien skizofrenia berdasarkan umur

Menurut Yosep (2011) faktor yang mempengaruhi pada penyakit skizofrenia bisa karena faktor jenis kelamin dan usia. Skizofrenia paling sering terjadi pada usia akhir masa remaja atau dewasa awal dan jarang terjadi saat belum memasuki usia remaja atau setelah usia 40 tahun, karena rentang usia tersebut merupakan usia produktif yang dipengaruhi banyaknya hal yang dipikirkan serta faktor pencetus stress lainnya dan usia tersebut adalah usia dimana individu sudah memiliki beban tanggungjawab yang cukup besar.

\section{3) Jenis Skizofrenia}

Hasil penelitian berdasarkan tabel 1 menunjukkan bahwa jenis skizofrenia di Poli Jiwa Rawat Jalan RSUD dr. H. Moch. Ansari Saleh Banjarmasin menunjukkan prevalensi tarbanyak adalah jenis skizofrenia tak terinci berjumlah 28 orang (56\%). Jenis skizofrenia ini mempunyai gejala positif (halusinasi dan delusi/waham) yang menonjol atau memenuhi kriteria skizofrenia tetapi tidak dapat digolongkan pada jenis skizofrenia yang lain. Jenis skizofrenia paranoid merupakan jenis terbanyak kedua berjumlah 22 orang (44\%) menurut Kaplan (2012) gejala yang mencolok dari skizofrenia paranoid ialah adanya keyakinan yang tidak rasional (waham, halusinasi, dengan pemerikasaan yang teliti ternyata adanya gangguan proses berpikir, gangguan efek emosi dan kemauan. Untuk jenis skizofrenia hebefrenik, katatonia dan simplek tidak ditemukan pada saat dilakukan penelitian, karena jenis skizofrenia tersebut jarang terjadi. Grafik dapat dilihat pada gambar 3 berikut: 


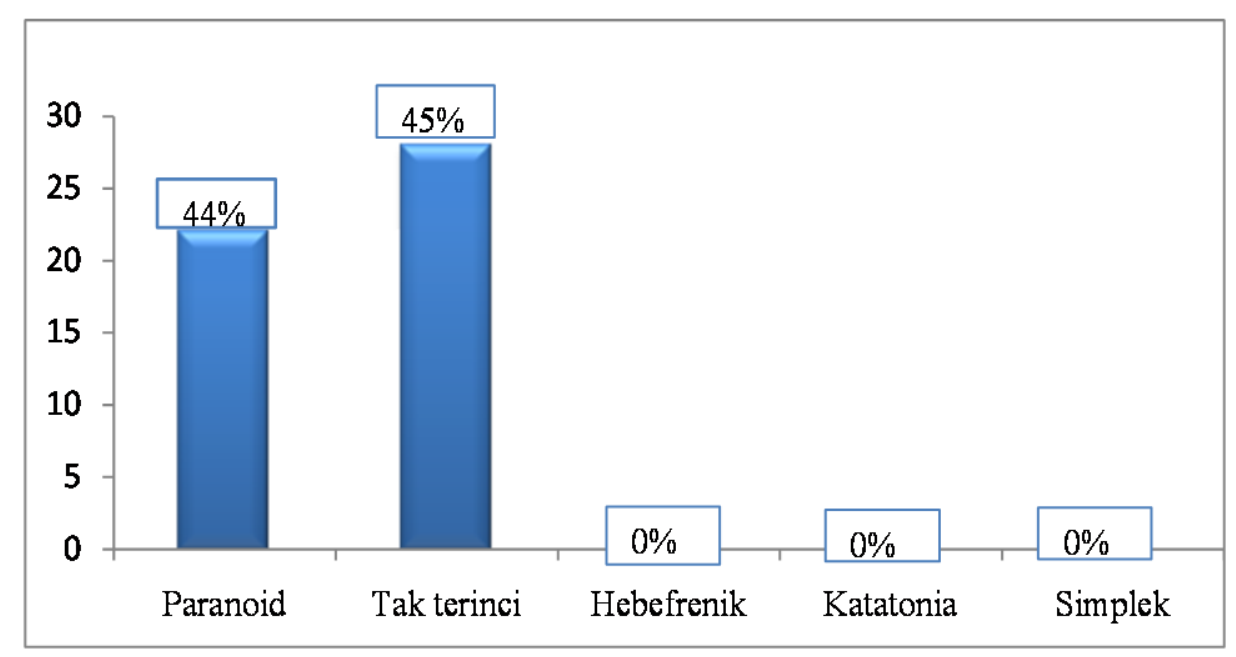

Gambar 3. Jenis Skizoprenia

\section{KESIMPULAN}

Dari hasil penelitian dengan jumlah sampel sebanyak 50 pasien, dapat disimpulkan bahwa :

a. Karakteristik pasien skizofrenia berdasarkan jenis kelamin laki-laki sebesar $56 \%$ dan perempuan sebesar $44 \%$,

b. Karakteristik berdasarkan umur paling banyak terjadi pada rentang 22-45 tahun sebesar $52 \%$

c. Karakteristik berdasarkan jenis skizofrenia paranoid sebesar $44 \%$ dan tak terinci sebesar $45 \%$.

\section{DAFTAR PUSTAKA}

Agung, W., \& Arulita, I. F. (2016). Faktor Resiko Terjadinya Skizofrenia. Public Health Perspektive Journal 1(1).

Kaplan, H. I., Sadock, B. J., \&Grebb, J. A., (2012). Kaplan-Sadock Sinopsis Psikiatri IImu Pengetahuan Perilaku Psikiatri Klinis Jilid 2. Jakarta: Binanupa Aksara.

Naafi, A. M., Perwitasari, D. A., \& Darmawan, E. (2016). Kepatuhan Minum Obat Pasien Rawat Jalan Skizofrenia di Rumah Sakit Jiwa Prof. dr. Soerojo Magelang.Kartika Jurnal Ilmiah Farmasi. 4(2), 7-12.

Riskesdas. (2013). Riset Kesehatan Dasar. Jakarta: Badan Penelitian dan pengembangan Kesehatan Kementrian Kesehatan RI.

Videbeck., Sheila, L. (2008). Buku Ajar Keperawatan Jiwa. Jakarta: EGC.

Videbeck, S.L, 2011. Psychiatric mental health nursing $\left(5^{\text {th }}\right.$ Ed). Lippincott Williams \& Wilkins.

Yosep, I. (2011). Keperawatan Jiwa (Edisi Revisi). Refilan Aditama : Bandung 